\title{
Summary of Application of Vehicle Radiation Environmental Monitoring System
}

\author{
Jiawen Fan, Jie Xu, Xuan Qin \\ Chengdu University of Technology, Chengdu, China \\ Email: 1533386277@qq.com
}

How to cite this paper: Fan, J.W., Xu, J. and Qin, X. (2021) Summary of Application of Vehicle Radiation Environmental Monitoring System. Open Access Library Journal, 8: e7399.

https://doi.org/10.4236/oalib.1107399

Received: April 9, 2021

Accepted: May 14, 2021

Published: May 17, 2021

Copyright $\odot 2021$ by author(s) and Open Access Library Inc.

This work is licensed under the Creative Commons Attribution International License (CC BY 4.0).

http://creativecommons.org/licenses/by/4.0/

(c) (i) Open Access

\begin{abstract}
The vehicle-borne radiation environmental monitoring system is not restricted by time, location and weather, and in the event of a sudden nuclear accident, it can quickly enter the accident site and monitor the ambient reflectivity level and absorbed air dose rate at the first time. At the same time, the vehicle-borne data communication and processing system is used to transmit the real-time data to the platform of emergency monitoring and dispatching, which provides powerful technical support for accurate radioactive evaluation and emergency decision-making. At present, domestic and foreign research on vehicle-borne environmental radiation monitoring system is more extensive, but there are fewer summary articles. In this paper, the application and development direction of the vehicle-borne radiation environmental monitoring system are briefly described, and some suggestions are proposed for establishing of corresponding dose correction methods and technical regulations according to the problems faced by the existing technology.
\end{abstract}

\section{Subject Areas}

Electric Engineering, Industrial Engineering

\section{Keywords}

Vehicle Radiation Environmental Monitoring, Nuclear Emergency, Environmental Dose Correction

\section{Introduction}

In the process of using nuclear energy, human beings are faced with various challenges such as nuclear leakage and nuclear pollution. In view of the sudden occurrence of nuclear accidents, it is easy to cause serious impacts on the sur- 
rounding environment and the public, so nuclear related countries all over the world attach great importance to the safe application of nuclear energy and establish perfect nuclear emergency systems [1]. As an important part of the emergency system, nuclear radiation emergency detection is a dynamic real-time monitoring, which requires rapid response to accidents, so as to provide technical basis for dose control and protection actions.

The traditional radiation environmental monitoring system can be divided into fixed detection system and mobile detection system. As a kind of mobile detection, the on-board nuclear accident emergency monitoring system has lower cost than aviation emergency monitoring, and can basically cope with small and medium-sized inland nuclear accidents, so it has been widely used in nuclear and radiation environmental monitoring [2]. However, due to the lack of appropriate calibration techniques, the measured data can only be used for qualitative analysis of radioactivity levels, but not for accurate dose description. Based on the research status of vehicle borne nuclear accident emergency monitoring system at home and abroad, this paper discusses the following four aspects: firstly, the application of vehicle borne radiation environmental monitoring system is described simply; then, the development direction of the monitoring system is discussed based on the international research status; further, the problems faced by the current vehicle borne radiation environmental monitoring system are discussed; finally, the corresponding research suggestions are given for the existing problems.

\section{Application of Vehicle Borne Radiation Environmental Monitoring System}

Vehicle borne radiation environmental monitoring system is a kind of detection equipment which uses the gamma spectrometer installed on the vehicle to measure the type and content of radionuclides in the ground and the absorbed dose rate of air along the road [3]. It is usually composed of environmental detection vehicle, gamma spectrometer, satellite positioning system, data receiving and processing terminal, which can respond to sudden nuclear accident and nuclear leakage in time.

The existing vehicle borne radiation environmental monitoring system is developed from the airborne gamma measurement system. Due to the limitation of airborne gamma measurement system in cities, such as flight altitude, terrain fluctuation, weather change, air traffic control and other conditions, some areas cannot be measured, resulting in incomplete measurement data [4]. The vehicle borne gamma spectrum measurement system can well complete the urban radiation detection, as is a mobile radiation detection method which is widely used at present. If the fixed environment detection equipment is damaged due to external factors after the nuclear accident, the vehicle borne radiation environmental monitoring has good mobility, which can replace the damaged fixed environment monitoring system in time. For example, in the Fukushima nuclear 
accident in 2011, because the earthquake and tsunami destroyed the fixed radiation monitoring equipment of the local government, it was unable to carry out environmental radiation monitoring in time, Tokyo Electric Power Company immediately used the on-board radiation environmental monitoring equipment to carry out real-time detection of air absorbed dose rate in the surrounding environment.

\section{Development Direction of Vehicle-Borne Environmental Radiation Monitoring System}

Since the early 1980s, developed countries such as the United States, Canada and Japan have successfully developed vehicle-borne environmental radiation monitoring systems for environmental radiation monitoring around nuclear power plants and other nuclear energy facilities. Currently in the international leading level are: Radiation Emergency Response Team Equipped (ERT) by the Environmental Protection Agency, Environmental Radiation Monitoring Vehicle Mobile Laboratory produced by German Target Company [5]. The above vehicle-borne systems are equipped with a variety of portable radiation detectors or laboratory radiation monitoring systems, which can quickly conduct radioactive dose monitoring and energy spectrum analysis.

At present, the research of hardware equipment for vehicle-borne radiation environment detection system is relatively mature. The accurate measurement of the gamma environmental dose rate is still the focus of scholars at home and abroad. In 1962, W. M. Lowder and H. L. Beck began to study how to determine the activity concentration of natural and artificial radionuclides in soil by in situ gamma spectrometry, thereby calculating the air absorption dose rate [6]. After decades of research, the application of gamma spectrum method in environmental science has become more mature, and the International Atomic Energy Agency (IAEA) and the International Commission on Radiation Units and Measurements (ICRU) have recommended gamma spectrum methods for estimating the air absorption dose rate in issued publications [7]. In 1971, Moriuchi first proposed the spectroscopy-dose rate function $(\mathrm{G}(\mathrm{E}))$ to achieve the measurement of dose rate. The ambient dose rate can be expressed as follow.

$$
\dot{D}=\sum_{0}^{E \max } N(E) G(E) d E / T
$$

where $N(E)$ is the energy spectrum measured by the $\mathrm{NaI}(\mathrm{Tl})$ crystal detector. In recent years, the spectroscopy-dose rate conversion method has been widely used in vehicle-borne environmental radiation monitoring systems to determine the ambient dose rate and the nuclide contribution to the ambient dose rate [8] [9] [10].

\section{Problems Faced by Vehicle-Borne Environmental Radiation Monitoring Systems}

Currently, there is still no corresponding national standard for vehicle-borne 
environmental radiation monitoring technology, the industry standard of "Vehicle-mounted Gamma Energy Spectrometry Measurement System" (EJ/T 585-1991) and "Vehicle-mounted Gamma Energy Spectrometry Measurement Specification" (EJ/T 980-1995) was developed mainly to regulate the radioactive mineral exploration and basic geological research, and is not applicable to the current radiation environment detection. At the same time, the vehicle-borne radiation environmental detection system is now widely used in environmental radiation monitoring, nuclear and radiation accident emergency monitoring, and has become the main mobile emergency equipment for nuclear accidents. However, in the existing technology, it is generally only used to qualitatively analyze the environmental radioactivity level, and cannot accurately describe the ambient radioactivity level or absorption dose rate. In addition, when using different mobile measurement equipment to measure absorbed air dose rates, due to the influence of detector height and shielding equipment, the same location measured results have a certain difference. Therefore, a series of complex calibration methods are needed to correct the dose of the measured data.

\section{Suggestions}

As the main equipment for radiation environmental quality monitoring and nuclear accident emergency monitoring, the vehicle-borne radiation environment detection system has various designs, the working environment is complex and changeable, and factors such as detection distance, angular response, and lower detection limit can affect the accuracy and reliability of its measurement results.

In view of the current problems faced by the above-mentioned vehicle-borne radiation environmental monitoring system, it is recommended that the environmental protection department carry out corresponding research on vehicle-borne radiation monitoring technology and establish suitable detection system scales, dose calibration methods and technical capabilities, and formulate relevant technical regulations, so that the data from vehicle-borne radiation environmental monitoring systems can be used for radiation environmental quality assessment, and effectively improve radiation environmental monitoring and nuclear accident emergency response capabilities.

\section{Summary}

Radiation environmental emergency monitoring is a kind of dynamic and real-time monitoring action implemented after a nuclear accident. The vehicle-borne radiation environmental measurement system has a good application prospect in radiation environmental monitoring activities at home and abroad by virtue of its strong mobility. Based on the main characteristics of the vehicle-borne radiation environmental monitoring system, this paper investigates the current research situation at home and abroad, and puts forward some corresponding suggestions for the existing problems in dose correction and oth- 
er aspects.

\section{Conflicts of Interest}

The authors declare no conflicts of interest regarding the publication of this paper.

\section{References}

[1] Mao, W.C., Xu, B. and Du, Y.Y. (2017) Vehicle-Mounted Radiation Environmental Monitoring Laboratory Data Acquisition and Transmission System. Sichuan Environment, 36, 99-103. (In Chinese)

[2] Ni, W.C. and Gu, R.K. (2003) Airborne Monitoring Method of Nuclear Emergency Response. Uranium Geology, No. 6, 366-373. (In Chinese)

[3] Yu, Z.L., Li, H.Y., Tang, L.L., et al. (2013) Discussion on the Application of Vehicle Radiation Monitoring Technology. The Administration and Technique of Environmental Monitoring, 25, 52-55. (In Chinese)

[4] Zhao, B.J. (2018) Research on Vehicle Gamma Spectrum Measurement System based on GIS. Chengdu University of Technology, Chengdu. (In Chinese)

[5] Wang, W. (2006) Research on Nuclear Accident Emergency Real-Time Mobile Monitoring System. Zhejiang University, Hangzhou. (In Chinese)

[6] Lowder, W.M., Beck, H.L. and Condon, W.J. (1964) Spectrometric Determination of Dose Rates from Natural and Fall-Out Gamma-Radiation in the United States, 1962-63. Nature, 202, 745-749. https://doi.org/10.1038/202745a0

[7] IAEA (1991) Airborne Gamma Ray Spectrometer Surveying. Technical Reports Series, No. 323, IAEA, Vienna.

[8] Ji, Y.Y., Chung, K.H., Lee, W., Park, D.W. and Kang, M.J. (2014) Feasibility on the Spectrometric Determination of the Individual Dose Rate for Detected Gamma Nuclides Using the Dose Rate Spectroscopy. Radiation Physics and Chemistry, 97, 172-177. https://doi.org/10.1016/j.radphyschem.2013.11.022

[9] Ji, Y.Y., Chung, K.H., Kim, C.J., Kang, M.J. and Park, S.T. (2015) Application of the Dose Rate Spectroscopy to the Dose-to-Curie Conversion Method Using a NaI(Tl) Detector. Radiation Physics and Chemistry, 106, 320-326. https://doi.org/10.1016/j.radphyschem.2014.08.009

[10] Ji, Y.Y., Chung, K.H. and Kang, M.J. (2020) Assessment of Dose Rate of detected Gamma Emitting Nuclides Using a Carborne Survey with a Large Volume NaI (Tl) Detector. Progress in Nuclear Energy, 123, Article ID: 103272.

https://doi.org/10.1016/j.pnucene.2020.103272 